\title{
Increased Neutrophil-lymphocyte and Platelet-lymphocyte Ratios in Male Heroin Addicts: A Prospective Controlled Study
}

\author{
Erdinc Cıcek ${ }^{1}$, Başak Demırel ${ }^{2}$, Ismet Esra Cıcek², Aslı Seda Kıraç², Ibrahim Eren ${ }^{2}$ \\ ${ }^{1}$ Department of Psychiatry, Çumra State Hospital, ${ }^{2}$ Department of Psychiatry, Research and Training Hospital, Konya, Turkey
}

\begin{abstract}
Objective: The neutrophil-lymphocyte ratio (NLR) and platelet-lymphocyte ratio (PLR) are markers that can determine the presence of systemic inflammatory response. In this study, we examined the NLR and PLR levels in patients with heroin dependence compared to healthy controls.

Methods: The study sample included 90 male patients with heroin dependence aged 18 to 45 years and 60 healthy subjects who had similar socio-demographic characteristics as the patient group. The diagnoses of heroin dependence and other Axis I psychiatric disorders in the patient and control groups were screened with the Structured Clinical Interview for Diagnostic and Statistical Manual of Mental Disorders, Fourth Edition (SCID-I). The extent of heroin addiction was assessed with the Addiction Severity Index (ASI).

Results: The mean NLR and PLR levels of patients with heroin dependence were significantly higher than the control subjects $(p=0.031$ and $p<0.001$, respectively). Positive correlations were found between NLR, PLR and duration of the disorder.

Conclusion: Our results indicate that inflammatory processes may play a role in the pathophysiology of heroin dependence.
\end{abstract}

KEY WORDS: Heroin; Dependency; Neutrophil-lymphocyte ratio; Platelet-lymphocyte ratio.

\section{INTRODUCTION}

Heroin dependence is defined as continuing heroin usage despite significant physical or psychological complications. ${ }^{1)}$ Heroin is the most commonly used opiate in the world. The lifetime prevalence of opioid use or its dependence has been reported to be $0.3 \%$ to $0.5 \%$ in the general population. ${ }^{2,3)}$

Alcohol/substance abuse disorders are accepted as a bio-psychosocial disorders and numerous risk factors such as socio-cultural, biological or genetic effects as well as psychological and individual differences are involved in the etiology of the disorders. ${ }^{4,5)}$

In recent years, it has been accepted that the biological

Received: March 6, 2017 / Revised: May 29, 2017 Accepted: July 3, 2017

Address for correspondence: Erdinc C1cek, MD Department of Psychiatry, Çumra State Hospital, İzzet Bey Mahallesi, Gazi Caddesi, Çumra 42500/Konya, Turkey Tel: +90-332-4475001, Fax: +90-332-4475500

E-mail: erdinccicek@yahoo.com.tr

ORCID: https://orcid.org/0000-0002-1477-810X basis of mental conditions also entails genetics, impairment in biochemical neurotransmission and receptor functions, and oxidative stress/antioxidant balance. ${ }^{6-8)}$ Furthermore, neuro-inflammatory processes play a significant role in both the etiology and progression of psychiatric disorders. ${ }^{9-11)}$ Evaluation of the relationship between opioid dependence and neuroinflammation indicated differences in the serum levels of cytokines like interleukin-1 $\beta$ (IL-1 $\beta$ ), IL-2, IL-4, IL-6, IL-8, interferon gamma (IFN- $\gamma)$ and tumor necrosis factor alfa (TNF- $\alpha){ }^{12-14)}$ Brain and plasma cytokine secretion was shown to be markedly increased in chronic opiate users and it was suggested that chronic opiate use could cause inflammation, neuronal degeneration and neuronal damage. ${ }^{14)}$

Some studies suggest that opiates such as heroin and morphine have adverse effects on the immune system. ${ }^{15,16)}$ Heroin, by affecting the opiate receptors on macrophages and lymphocytes directly ${ }^{17,18)}$ or in the central nervous system (CNS) indirectly, can change several physiological functions including immune system reactions in the body. ${ }^{19,20)}$

(ㄷ) This is an Open-Access article distributed under the terms of the Creative Commons Attribution Non-Commercial License (http://creativecommons.org/licenses/by-nc/4.0) which permits unrestricted non-commercial use, distribution, and reproduction in any medium, provided the original work is properly cited. 
The white blood cells (WBC), neutrophil and lymphocyte counts and neutrophil-lymphocyte ratio (NLR) are indicators of systemic inflammation. NLR and platelet-lymphocyte ratio (PLR) are markers that can be assessed easily and determine the presence of systemic inflammatory response. $^{21,22)}$ NLR and PLR were shown to be positively correlated with inflammatory markers including IL-6 and TNF- $\alpha{ }^{23)}$ In addition to inflammation, NLR was also considered to reflect inflammation in blood vessel wall while PLR was indicative of high blood viscosity. ${ }^{24)}$ Moreover, PLR was found to be a more sensitive marker of inflammation than NLR. ${ }^{25,26)}$ NLR has been evaluated in psychiatric disorders such as Alzheimer disease, schizophrenia, bipolar disorder and depression. ${ }^{27-31)}$ NLR was found to increase in these disorders and was considered to be an indicator of increased inflammation.

NLR has been determined in the context of chronic stress in animal studies. ${ }^{32,33)}$ Moreover, increased NLR has been reported to be related to oxidative stress and increased cytokine production, both of which are seen in heroin dependence. ${ }^{34)}$ However, to our knowledge, there is no published study that has evaluated NLR and PLR in heroin addicts. Therefore, the aim of this study was to investigate NLR and PLR in patients with heroin dependence compared to healthy subjects.

\section{METHODS}

\section{Sample}

This controlled study included 90 consecutive male heroin addict patients between 18 and 45 years of age who were admitted to a psychiatry clinic. All patients had a positive urine opioid test and were treated with buprenorphine. The exclusion criteria were as follows: any additional substance use disorder (except smoking), other psychiatric disorders, obesity, presence of acute or chronic hormonal, inflammatory and autoimmune disorder, presence of a severe medical disease (e.g., cardiovascular and pulmonary system diseases, neurological diseases, hepatic and renal failure), presence of active infection, treatment with anti-inflammatory and immunosuppressive drugs, abnormalities in laboratory tests (e.g., anemia, thrombocytopenia, leukocytosis, leukopenia etc.) and lack of a blood sample.

The control group consisted of 60 healthy male hospital employees between 18 and 45 years of age. The patient and control groups had similar demographic characteristics in terms of age, education and smoking habits. The control subjects had not undergone any medical treatment for 6 weeks prior to providing blood samples. Moreover, they had no history of psychiatric, neurological or medical disorders.

\section{Procedure}

The procedures and objectives of the study were explained to the participants by a psychiatrist and written informed consent was obtained from all participants. The study procedure was approved by the ethics committee of the Faculty of Medicine of Selcuk University (No. 2016/29). A semi-structured interview form developed by the researchers was used to collect data on the demographic and clinical characteristics of the participants. The Structured Clinical Interview for Diagnostic and Statistical Manual of Mental Disorders, Fourth Edition (SCID-I) was used for the diagnoses of heroin addiction and other Axis I psychiatric disorders in patient and control groups. ${ }^{35,36)}$ The severity of symptoms of heroin dependence in the patients was assessed with the Addiction Severity Index (ASI). ASI is a semi-structured interview that was developed by McLellan et al. ${ }^{37)}$ The Turkish version of ASI contains 140 items with scores between 0 and 9 and assesses 6 different dimensions: medical status, employment/support status, drug/alcohol use, legal status, family/social status and psychiatric status. Higher scores correspond to greater severity of the addiction. The validity and reliability study of the Turkish version was carried out by Demirbaş et al. ${ }^{38)}$ Following psychiatric evaluations, samples for laboratory tests were obtained from the participants.

The blood samples were taken from the left forearm vein after 12 hours of fasting during a routine laboratory evaluation. For the complete blood count, the blood samples were drawn into vacutainer tubes that included ethylenediaminetetraacetic acid as an anticoagulant and the samples were analyzed in an automatic blood cell counter (Abbott CELL-DYN 3700; Abbott Laboratories, Abbott Park, IL, USA).

\section{Statistical Analysis}

The data were analyzed using the PASW Statistics version 18.0 for Windows (IBM Co., Armonk, NY, USA). The data are presented as mean \pm standard deviation and per- 
cent ratio. All variables were checked with the Kolmogorov-Smirnov test to determine whether the test distributions were normal or not. Normally distributed variables were compared using $t$ test. Variables that did not have normal distributions were compared with the Mann-Whitney $U$ test. One-way ANOVA was utilized for more than two independent groups. Chi-square test was used to compare categorical variables. Linear association between the variables was examined by Pearson correlation analysis. All significant levels were 2-tailed and set at the level of 0.05 .

\section{RESULTS}

The mean age of the participants of this study $(n=150)$ was found to be $23.28 \pm 3.71$ years. There were no significant differences between the patient and control groups in terms of age $(\mathrm{t}=0.84, p=0.42)$ and education level $(\mathrm{t}=-0.25, p=0.80)$. The mean age of onset of heroin use was $19.54 \pm 3.98$ years and the mean duration of the dis- order at the time of study was $3.90 \pm 2.77$ years (Table 1).

The NLR was significantly higher in patients with heroin dependence than control subjects $(1.86 \pm 0.89$ vs. $1.30 \pm 0.31 ; p=0.011$ ). Additionally, the patients had significantly higher PLR compared to the control subjects (112.0 \pm 50.4 vs. $88.95 \pm 24.6 ; p<0.001)$. Heroin dependent patients had significantly more neutrophil $(4.46 \pm 1.64$ and $3.76 \pm 0.80$, respectively) and platelet $(284.2 \pm 79.67$ and $253.2 \pm 54.70$, respectively) counts compared to the control subjects.

The NLR and PLR levels were significantly higher in the patients with injecting heroin intravenously compared to control subjects $(p<0.05)$. There were also no significant differences between the patients and controls in terms of other blood count parameters (Table 2). Pearson correlation analysis showed that NLR and PLR were positively correlated with the duration of the disorder $(p=0.000)$. However, NLR and PLR were not significantly correlated with age of onset of heroin use and severity of the disorder $(p>0.05)$ (Table 3).

Table 1. Characteristics of groups

\begin{tabular}{|c|c|c|c|c|}
\hline \multirow{2}{*}{ Characteristic } & \multicolumn{2}{|c|}{ Group } & \multirow{2}{*}{$t / U$} & \multirow{2}{*}{$p$ value } \\
\hline & Patient $(n=90)$ & Control $(n=60)$ & & \\
\hline Age (yr) & $23.48 \pm 4.11$ & $22.98 \pm 3.01$ & $0.798^{*}$ & 0.426 \\
\hline Duration of education (yr) & $8.34 \pm 2.47$ & $8.45 \pm 2.50$ & $0.255^{\dagger}$ & 0.800 \\
\hline \multicolumn{5}{|l|}{ Method of drug use (\%) } \\
\hline Inhalation & 68.9 & & & \\
\hline Intravenous & 31.1 & & & \\
\hline Age of onset of heroin use (yr) & $19.54 \pm 3.98$ & - & & \\
\hline Duration of disorder (yr) & $3.90 \pm 2.77$ & - & & \\
\hline
\end{tabular}

Values are presented as mean \pm standard deviation or percent only.

${ }^{*} t$ test; ${ }^{\dagger}$ Mann-Whitney $U$ test.

Table 2. Comparison of blood count parameters between patients with heroin dependence and healthy controls

\begin{tabular}{|c|c|c|c|c|}
\hline \multirow{2}{*}{ Parameter } & \multicolumn{2}{|c|}{ Group } & \multirow{2}{*}{$t / U$} & \multirow{2}{*}{$p$ value } \\
\hline & Patient $(n=90)$ & Control $(n=60)$ & & \\
\hline Hemoglobin (g/dl) & $14.98 \pm 1.77$ & $14.78 \pm 1.31$ & $0.733^{*}$ & 0.438 \\
\hline White blood cell count $\left(10^{3} / \mathrm{mm}^{3}\right)$ & $8.05 \pm 1.95$ & $7.51 \pm 1.66$ & $1.764^{*}$ & 0.080 \\
\hline Neutrophil $\left(10^{3} / \mathrm{mm}^{3}\right)$ & $4.46 \pm 1.64$ & $3.76 \pm 0.80$ & $3.059^{*}$ & 0.030 \\
\hline Lymphocyte $\left(10^{3} / \mathrm{mm}^{3}\right)$ & $2.74 \pm 0.69$ & $2.99 \pm 0.84$ & $2.010^{\dagger}$ & 0.056 \\
\hline Platelet $\left(10^{3} / \mathrm{mm}^{3}\right)$ & $284.2 \pm 79.67$ & $253.2 \pm 54.70$ & $2.631^{\dagger}$ & 0.009 \\
\hline NLR & $1.86 \pm 0.89$ & $1.30 \pm 0.31$ & $2.590^{*}$ & 0.011 \\
\hline PLR & $112.0 \pm 50.4$ & $88.95 \pm 24.6$ & $3.299^{*}$ & $<0.001$ \\
\hline
\end{tabular}

Values are presented as mean \pm standard deviation.

NLR, neutrophil- lymphocyte ratio; PLR, platelet-lymphocyte ratio.

${ }^{*} t$ test; ${ }^{\dagger}$ Mann-Whitney $U$ test. 
Table 3. The correlations between NLR, PLR, and ASI scores of participants

\begin{tabular}{|c|c|c|c|c|c|c|c|c|c|c|c|}
\hline & & \multirow[b]{2}{*}{ NLR } & \multirow[b]{2}{*}{ PLR } & \multirow{2}{*}{$\begin{array}{l}\text { Duration of } \\
\text { disorder }\end{array}$} & \multirow{2}{*}{$\begin{array}{l}\text { Age of onset } \\
\text { of heroin } \\
\text { use }\end{array}$} & \multicolumn{6}{|c|}{ ASI } \\
\hline & & & & & & Medical & $\begin{array}{c}\text { Employment } \\
\text { /support }\end{array}$ & Legal & Drug & Family/social & Psychiatric \\
\hline NLR & $r$ & & $0.733^{*}$ & $0.388^{*}$ & & & & & & & \\
\hline PLR & $r$ & $0.733^{*}$ & & $0.420^{*}$ & & & & & & & \\
\hline
\end{tabular}

NLR, neutrophil- lymphocyte ratio; PLR, platelet-lymphocyte ratio; ASI, Addiction Severity Index. ${ }^{*} p<0.01$.

\section{DISCUSSION}

To our knowledge, this is the first study to evaluate PLR and NLR in patients with heroin dependence and showed that both ratios were higher in patients with heroin dependence when compared to healthy controls. Moreover, there was a statistically significant correlation between the duration of the disorder and PLR and NLR.

Several studies have examined NLR in psychiatric disorders such as Alzheimer disease, ${ }^{27)}$ schizophrenia, ${ }^{28)}$ bipolar disorder, ${ }^{29)}$ and depression. ${ }^{30,31)}$ Kuyumcu et al. ${ }^{27)}$ demonstrated that NLR of patients with Alzheimer disease was higher than individuals with normal cognitive functions. Semiz et al. ${ }^{28)}$ reported that schizophrenia patients had higher NLR compared to healthy subjects. Additionally, Çakır et al. ${ }^{39)}$ found that NLR levels were higher in patients with bipolar disorders compared to healthy individuals. Demir et al. ${ }^{30)}$ and Demircan et al. ${ }^{31)}$ found that NLR levels were significantly higher in patients with major depression compared to control subjects. Similarly, Kalelioglu et al. ${ }^{29)}$ demonstrated that NLR levels were higher in both manic and euthymic patients with bipolar disorder compared to healthy individuals. Moreover, in a study by Kalelioglu et al. ${ }^{29)}$ PLR levels were also higher in the patient group compared to healthy controls. In these studies, the high NLR and PLR levels were ascribed to increased inflammation, which might play a role in the etiology of these disorders. Corroborating these data, in the current study we found that patients with heroin dependence had higher NLR and PLR values compared to healthy controls.

An analysis of inflammatory parameters in opiate addicts in the literature indicated that increased levels of cytokines, acute phase reactants, immunoglobulin (Ig) G, and IgM were seen in addicts when compared to healthy individuals. $^{12,14,40)}$ Chan et al. ${ }^{14)}$ reported that IL-1 $\beta$, IL-6 and IL-8 levels were significantly higher in patients with heroin dependence than healthy controls. In another study, the plasma TNF- $\alpha$ and IL-8 levels were found to be significantly higher in long-term heroin dependent patients than healthy controls and these levels were significantly decreased after 12 weeks of treatment. ${ }^{12)}$ Reece $^{41)}$ reported that compared to healthy controls, immune parameters like C-reactive protein, erythrocyte sedimentation rate, total lymphocyte count, serum globulin and globulin to albumin ratio were higher in opioid dependent patients. Wang et al. ${ }^{40)}$ reported that IFN- $\gamma, \operatorname{IgG}$ and IgM levels were significantly higher in heroin users compared to healthy controls. Specifically, IFN- $\gamma$ level was found to be higher between days 0 and 28 and this level was decreased on day 84 in heroin users. IgG and IgM levels in heroin users were found to be higher than the healthy control group in 12 weeks ofthe study period. ${ }^{40)}$ White blood cells, particularly neutrophils, play very important roles in the inflammatory process; therefore, white blood cell countis considered to be an important determinant of chronic inflammation. Additionally, platelets play an important role in atherogenesis, particularly in the development of inflammation. ${ }^{42,43)}$ Platelets can interact with several cell types such as endothelial cells, T lymphocytes, neutrophils and mononuclear phagocytes. It has been reported that platelets can initiate andaggravate inflammation on the arterial wall as a result of its interactions with other cell types. ${ }^{44)}$ Increasing evidence shows that interaction of platelets with leukocytes on vessel wallscan induce inflammation. ${ }^{45)}$ In the current study we found decreased number of lymphocytes and increased total WBC, neutrophil and platelet counts in patients with heroin dependence compared to healthy controls. Additionally, NLR and PLR, which are the markers of inflammation, were higher in the patients than the control subjects. Therefore, NLR and PLR can be used as a marker for inflammation in heroin addicts.

NLR and PLR levels were also found to be associated 
with the duration of disorder in the current study. Serum immunoglobulin levels have previously been shown to be correlated with the duration of heroin dependence. ${ }^{40,46)}$ Chen et al. ${ }^{12)}$ reported that TNF- $\alpha$ and IL-8 levels were significantly elevated in patients who used heroin for longer periods. Chronic opiate use may increase cytokine secretion in the plasma and brain causing inflammation, neuronal degeneration and neuronal damage in the peripheral and CNSs. It is suggested that this neuronal damage could be related to a drug seeking behavior. ${ }^{12)}$ This further supports our hypothesis that long-term heroin use might cause systemic inflammation.

In our study, patients who injected heroin intravenously exhibited significantly increased NLR and PLR compared to control subjects. Several studies have revealed the association of injection drug use with increase in inflammatory mediators. ${ }^{12,47)}$ In these studies serum IL-1 $\beta$, IL-6, IL-8, IL-10, TNF- $\alpha$, and transforming growth factor- $\alpha$ levels were increased in heroin addicts compared to control subjects. Additionally, Piepenbrink et al. ${ }^{47)}$ showed that injection drug users had significantly higher $\operatorname{lgG}_{3}, \operatorname{lgG}_{4}$, and $\lg M$ levels than healthy controls. These authors suggested that injection drug users showed broad alterations in the profile of the humoral immune system, which was also indicative of systemic inflammation. Such dysregulation may impair the ability of injection drug users to generate optimal responses to vaccination and infection, or lead to increased risk for inflammation-related comorbidities.

The limitations of the study can be listed as the following: (a) A relatively small sample size, which decreased the power of specific analyses; (b) The inclusion of only male patients in the study; (c) Other inflammatory markers such as CRP and cytokines were not evaluated; (d) the amount of heroin used was not evaluated; (e) The influence of smoking on inflammation cannot be excluded due to the fact that all of the patients who participated in the study were also smokers.

In conclusion, our results show that NLR and PLR levels were statistically significantly higher in patients with heroin dependence compared to healthy subjects. Thus, inflammatory processes may play a role in the pathophysiology of heroin dependence. Further comprehensive studies are needed with a larger sample size in order to better understand the relationship between inflammation and high NLR and PLR in heroin dependence.

\section{REFERENCES}

1. American Psychiatric Association. Diagnostic and Statistical Manual of Mental Disorders: DSM-5. 5th ed. Washington D.C.:American Psychiatric Association;2013.

2. United Nations Office on Drugs and Crime. World drug report 2010. New York:United Nations Publications;2010.

3. Merikangas KR, McClair VL. Epidemiology of substance use disorders. Hum Genet 2012;131:779-789.

4. Sadock BJ, Sadock VA, Aydin H, Bozkurt A. Kaplan and Sadock's comprehensive textbook of psychiatry. 8th ed. Ankara:Güneş Kitabevi;2007.

5. Ögel K. Alkol ve Madde Kullanım bozuklukları: Tanı, Tedavi ve Önleme. İstanbul:Yeniden Yayınları;2010. Turkish.

6. Camkurt MA, Karababa F, Erdal ME, Bayazıt H, Kandemir SB, Ay $\mathrm{ME}$, et al. Investigation of dysregulation of several MicroRNAs in peripheral blood of schizophrenia patients. Clin Psychopharmacol Neurosci 2016;14:256-260.

7. Camkurt MA, Findıklı E, Bakacak M, Tolun Fİ, Karaaslan MF. Evaluation of malondialdehyde, superoxide dismutase and catalase activity in fetal cord blood of depressed mothers. Clin Psychopharmacol Neurosci 2017;15:35-39.

8. Agrawal R, Kalmady SV, Venkatasubramanian G. In silico model-driven assessment of the effects of brain-derived neurotrophic factor deficiency on glutamate and gamma-aminobutyric acid: implications for understanding schizophrenia pathophysiology. Clin Psychopharmacol Neurosci 2017;15: 115-125.

9. Kim YK, Jung HG, Myint AM, Kim H, Park SH. Imbalance between pro-inflammatory and anti-inflammatory cytokines in bipolar disorder. J Affect Disord 2007; 104:91-95.

10. Brietzke E, Kauer-Sant'Anna M, Teixeira AL, Kapczinski F. Abnormalities in serum chemokine levels in euthymic patients with bipolar disorder. Brain Behav Immun 2009;23: 1079-1082.

11. Na KS, Jung HY, Kim YK. The role of pro-inflammatory cytokines in the neuroinflammation and neurogenesis of schizophrenia. Prog Neuropsychopharmacol Biol Psychiatry 2014;48:277-286.

12. Chen SL, Lee SY, Tao PL, Chang YH, Chen $\mathrm{SH}$, Chu CH, et al. Dextromethorphan attenuated inflammation and combined opioid use in humans undergoing methadone maintenance treatment. J Neuroimmune Pharmacol 2012;7:1025-1033.

13. Pacifici R, di Carlo S, Bacosi A, Pichini S, Zuccaro P. Pharmacokinetics and cytokine production in heroin and morphine-treated mice. Int I Immunopharmacol 2000;22: 603-614.

14. Chan YY, Yang SN, Lin JC, Chang JL, Lin JG, Lo WY. Inflammatory response in heroin addicts undergoing methadone maintenance treatment. Psychiatry Res 2015;226:230234.

15. Sacerdote P. Opioids and the immune system. Palliat Med 2006;20 Suppl 1:s9-s15.

16. Vallejo R, de Leon-Casasola O, Benyamin R. Opioid therapy 
and immunosuppression: a review. Am J Ther 2004;11:354365.

17. Nelson CJ, Schneider GM, Lysle DT. Involvement of central mu- but not delta- or kappa-opioid receptors in immunomodulation. Brain Behav Immun 2000;14:170-184.

18. Stefano GB, Scharrer B, Smith EM, Hughes TK Jr, Magazine HI, Bilfinger TV, et al. Opioid and opiate immunoregulatory processes. Crit Rev Immunol 1996;16:109-144.

19. Fecho K, Maslonek KA, Dykstra LA, Lysle DT. Assessment of the involvement of central nervous system and peripheral opioid receptors in the immunomodulatory effects of acute morphine treatment in rats. J Pharmacol Exp Ther 1996;276: 626-636

20. McCarthy L, Wetzel M, Sliker JK, Eisenstein TK, Rogers TJ. Opioids, opioid receptors, and the immune response. Drug Alcohol Depend 2001;62:111-123.

21. Balta S, Ozturk C. The platelet-lymphocyte ratio: a simple, inexpensive and rapid prognostic marker for cardiovascular events. Platelets 2015;26:680-681.

22. Zahorec R. Ratio of neutrophil to lymphocyte counts--rapid and simple parameter of systemic inflammation and stress in critically ill. Bratis/ Lek Listy 2001;102:5-14.

23. Turkmen K, Erdur FM, Ozcicek F, Ozcicek A, Akbas EM, Ozbicer A, et al. Platelet-to-lymphocyte ratio better predicts inflammation than neutrophil-to-lymphocyte ratio in end-stage renal disease patients. Hemodial Int 2013;17:391-396.

24. Gary T, Pichler M, Belaj K, Hafner F, Gerger A, Froehlich H, et al. Platelet-to-lymphocyte ratio: a novel marker for critical limb ischemia in peripheral arterial occlusive disease patients. PLoS One 2013;8:e67688.

25. Kwon HC, Kim SH, Oh SY, Lee S, Lee JH, Choi HJ, et al. Clinical significance of preoperative neutrophil-lymphocyte versus platelet-lymphocyte ratio in patients with operable colorectal cancer. Biomarkers 2012;17:216-222.

26. Bhatti I, Peacock O, Lloyd G, Larvin M, Hall RI. Preoperative hematologic markers as independent predictors of prognosis in resected pancreatic ductal adenocarcinoma: neutrophillymphocyte versus platelet-lymphocyte ratio. Am I Surg 2010;200:197-203.

27. Kuyumcu ME, Yesil Y, Oztürk ZA, Kizilarslanoğlu C, Etgül S, Halil M, et al. The evaluation of neutrophil-lymphocyte ratio in Alzheimer's disease. Dement Geriatr Cogn Disord 2012; 34:69-74.

28. Semiz M, Yildirim O, Canan F, Demir S, Hasbek E, Tuman TC, et al. Elevated neutrophil/lymphocyte ratio in patients with schizophrenia. Psychiatr Danub 2014;26:220-225.

29. Kalelioglu T, Akkus M, Karamustafalioglu N, Genc A, Genc ES, Cansiz A, et al. Neutrophil-lymphocyte and platelet-lymphocyte ratios as inflammation markers for bipolar disorder. Psychiatry Res 2015;228:925-927.

30. Demir S, Atli A, Bulut M, İbiloğlu AO, Güneş M, Kaya MC, et al. Neutrophil-lymphocyte ratio in patients with major depressive disorder undergoing no pharmacological therapy.
Neuropsychiatr Dis Treat 2015;11:2253-2258.

31. Demircan F, Gözel N, Kılınç F, Ulu R, Atmaca M. The impact of red blood cell distribution width and neutrophil/lymphocyte ratio on the diagnosis of major depressive disorder. Neurol Ther 2016;5:27-33.

32. Puppe B, Tuchscherer M, Tuchscherer A. The effect of housing conditions and social environment immediately after weaning on the agonistic behaviour, neutrophil/lymphocyte ratio, and plasma glucose level in pigs. Livest Prod Sci 1997;48: 157-164.

33. Trevisi E, Bertoni G. Some physiological and biochemical methods for acute and chronic stress evaluation in dairy cows. Ital J Anim Sci 2009;8(Supp/ 1):265-286.

34. Turkmen K, Tonbul HZ, Toker A, Gaipov A, Erdur FM, Cicekler $\mathrm{H}$, et al. The relationship between oxidative stress, inflammation, and atherosclerosis in renal transplant and end-stage renal disease patients. Ren Fail 2012;34:12291237.

35. First MB, Spitzer RL, Gibbon M, Williams JBW. User's guide for the structured clinical interview for DSM-IV axis / disorders SCID-I: clinician version. Washington, D.C.:American Psychiatric Press; 1997.

36. Özkürkçügil A, Aydemir Ö, Yildiz M, Esen Danaci A, Köroğlu IVE. [Adaptation and reliability study of Structured Clinical Interview for DSM-IV Axis I disorders]. Turk I Drug Ther 1999;12:233-236. Turkish.

37. McLellan AT, Kushner $\mathrm{H}$, Metzger D, Peters R, Smith I, Grissom G, et al. The fifth edition of the Addiction Severity Index. J Subst Abuse Treat 1992;9:199-213.

38. Demirbaş H, Ilhan I, Doğan Y. Bağımlılık Şiddetini Belirleme Ölçeğinin Geçerlik-Güvenilirlilik çalışması. Ankara:Ankara Üniversitesi Tip Fakültesi Psikiyatri Kliniği Doktora Tezi; 2003. Turkish.

39. Çakır U, Tuman TC, Yıldıım O. Increased neutrophil/lymphoctye ratio in patients with bipolar disorder: a preliminary study. Psychiatr Danub 2015;27:180-184.

40. Wang Z, Yang XR, Song H, Cao BR, Yin F, An ZM, et al. Immune function alterations during 12 weeks of abstinence in heroin users. Folia Biol (Praha) 2015;61:241-246.

41. Reece AS. Evidence of accelerated ageing in clinical drug addiction from immune, hepatic and metabolic biomarkers. Immun Ageing 2007;4:6.

42. Koyama H, Maeno T, Fukumoto S, Shoji T, Yamane T, Yokoyama $\mathrm{H}$, et al. Platelet $P$-selectin expression is associated with atherosclerotic wall thickness in carotid artery in humans. Circulation 2003; 108:524-529.

43. Shoji T, Koyama H, Fukumoto S, Maeno T, Yokoyama $\mathrm{H}$, Shinohara $\mathrm{K}$, et al. Platelet activation is associated with hypoadiponectinemia and carotid atherosclerosis. Atherosclerosis 2006;188:190-195.

44. Borissoff JI, Spronk HM, ten Cate H. The hemostatic system as a modulator of atherosclerosis. NEng/JMed 2011;364:17461760 . 
45. Langer HF, Gawaz M. Platelet-vesse/ wall interactions in atherosclerotic disease. Thromb Haemost 2008;99:480-486.

46. Nikolova M, Liubomirova M, Iliev A, Krasteva R, Andreev E, Radenkova J, et al. Clinical significance of antinuclear antibodies, anti-neutrophil cytoplasmic antibodies and anticardiolipin antibodies in heroin abusers. Isr Med Assoc J
2002;4(11 Suppl):908-910.

47. Piepenbrink MS, Samuel M, Zheng B, Carter B, Fucile C, Bunce $\mathrm{C}$, et al. Humoral dysregulation associated with increased systemic inflammation among injection heroin users. PLoS One 2016;11:e0158641. 